\title{
CONTROLE QUímico DE Rottboellia exaltata EM CANA-DE-AçúCAR ${ }^{1}$
}

\author{
Chemical Control of Rottboellia exaltata in Sugarcane
}

FREITAS, S.P. ${ }^{2}$, OLIVEIRA, A.R. ${ }^{3}$, FREITAS, S.J. ${ }^{4}$ e SOARES, L.M.S. ${ }^{4}$

\begin{abstract}
RESUMO - A Rottboellia exaltata é uma das mais importantes espécies de plantas daninhas da cultura da cana-de-açúcar da região Norte Fluminense, sendo responsável pela redução na produtividade da cultura e pelo aumento dos custos de produção. Com o objetivo de avaliar a eficiência de trifloxysulfuron-sodium+ametryn no controle de $R$. exaltata, foi realizado este trabalho em área com alta infestação desta espécie, utilizando o cultivar RB 72454. Utilizou-se o delineamento experimental em blocos casualizados, com quatro repetições. Os herbicidas foram aplicados em pós-emergência, utilizando-se pulverizador costal pressurizado, operando em pressão constante de $3,5 \mathrm{kgf} \mathrm{cm}^{-2}$, com bico XR 8003 e volume de calda de $250 \mathrm{~L} \mathrm{ha}^{-1}$. Aplicaram-se os seguintes tratamentos: MSMA+diuron, trifloxysulfuron-sodium+ametryn, trifloxysulfuron-sodium, ametryn, diuron+paraquat, testemunha com capina e testemunha sem capina. Os tratamentos MSMA+diuron, diuron+paraquat e trifloxysulfuron-sodium+ametryne, na maior dose, proporcionaram excelente controle de $R$. exaltata (acima de 90\%). Maiores produtividades de cana-de-açúcar foram obtidas nos tratamentos trifloxysulfuron-sodium+ametryne, MSMA+diuron e diuron+paraquat.
\end{abstract}

Palavras-chave: Trifloxysulfuron-sodium, capim-camalote, Saccharum spp., controle.

ABSTRACT - Rottboellia exaltata (itchgrass) is one of the major weeds infesting sugarcane in the Norte-Fluminense area, reducing culture yield and increasing production costs. The objective of this study was to evaluate the efficiency of trifloxysulfuron-sodium in controlling $\mathbf{R}$. exaltata. The experiment was installed in an area cultivated with the sugar cane cultivar RB 72454, on a randomized complete block design, with four replications. The herbicides were applied at postemergence with a pressurized knapsack sprayer, operating at a constant pressure of $3.5 \mathrm{kgf} \mathrm{cm}^{-2}$, nozzle XR 8003 and $250 \mathrm{~L} \mathrm{ha}^{-1}$. The following treatments were used: MSMA + diuron, trifloxysulfuron-sodium + ametryne, trifloxysulfuron-sodium, ametryne, diuron + paraquat,control with weeding and control without weeding. The herbicides MSMA + diuron, diuron + paraquat and trifloxysulfuron-sodium + ametryne provided excellent control of $\boldsymbol{R}$. exaltata (over 90\%) at the highest rate. The treatments providing the highest sugarcane yield were trifloxysulfuronsodium + ametryne, MSMA + diuron and diuron + paraquat.

Key words: Trifloxysulfuron-sodium, itchgrass, Saccharum spp., control.

Recebido para publicação em 10.6.2002 e na forma revisada em 10.9.2004.

2 Eng.-Agr., Doutor, Professor de Manejo de Plantas Daninhas da Universidade Estadual do Norte Fluminense Darcy Ribeiro UENF, Av. Alberto Lamego 2000 - Horto, 28013-602 Campos dos Goytacazes-RJ; ${ }^{3}$ Eng.-Agr., M.S., Doutorando em Produção Vegetal - UENF; ${ }^{4}$ Estudante de graduação - UENF, < silverio@uenf.br>

Planta Daninha, Viçosa-MG, v. 22, n. 3, p. 461-466, 2004 


\section{INTRODUÇÃO}

O Brasil é o maior produtor mundial de cana-de-açúcar, destacando-se os Estados de São Paulo, Paraná, Alagoas, Minas Gerais, Pernambuco e Rio de Janeiro. Na região Norte Fluminense, o plantio de cana-de-açúcar é secular e predominante no segmento industrial. A produção brasileira de cana-de-açúcar na safra de 2002/2003 atingiu 321,6 milhões de toneladas (Severo, 2003).

A flora infestante das lavouras canavieiras é bastante específica se comparada com a de outras culturas. O número de espécies é menor e constituído, geralmente, de plantas muito diferentes, ainda que separadas no espaço apenas por um carreador. Os efeitos microclimáticos, as interações de natureza química (alelopáticas) entre as plantas daninhas e a cultura e o uso contínuo de determinados insumos - como adubos, corretivos e herbicidas - são os principais responsáveis pela composição da flora infestante (Lorenzi, 1988).

O grau de interferência das plantas daninhas na cultura depende de diversos fatores relacionados à comunidade infestante, à própria cultura, à época e à duração do período de convivência (Pitelli, 1985; Constantin, 1993; Kuva et al., 2000). O período crítico da cultura da cana-de-açúcar devido à concorrência de plantas daninhas manifesta-se, em média, até 90 dias após a emergência (Kuva et al., 2003, 2001). O controle químico é mais eficiente nesse período através da utilização de herbicidas em pré-emergência, logo após o plantio e em área total, e/ou em pós-emergência, em aplicação dirigida ou em área total, conforme seletividade do herbicida (Mascarenhas et al., 1995).

O controle químico de plantas daninhas em áreas com cana-de-açúcar é uma prática bastante difundida em todo o país. Embora haja grande número de herbicidas recomendados para a cultura da cana-de-açúcar, pouco se sabe sobre a eficiência deles no controle de $R$. exaltata.

A espécie $R$. exaltata foi introduzida recentemente na região do Rio de Janeiro e infesta culturas anuais e perenes. Muito vigorosa e prolífica, uma única planta é capaz de emitir até 100 perfilhos e produzir 15.000 sementes, que ficam dormentes no solo por até quatro anos (Sharma \& Zelaya, 1986; Lorenzi, 2000).

Dentre as novas alternativas para o controle químico de plantas daninhas em canade-açúcar, tem-se destacado o herbicida trifloxysulfuron-sodium, que inibe a formação de proteínas em plantas suscetiveis, causando amarelecimento das folhas, parada do crescimento e morte destas em uma a três semanas após a aplicação (Oliveira Jr. et al., 2001). A tolerância da cana-de-açúcar ao trifloxysulfuron-sodium é baseada em dois mecanismos: aumento da degradação biológica, comparada às plantas suscetíveis, e muito baixa translocação do herbicida nas folhas tratadas. O trifloxysulfuron-sodium absorvido é imóvel em tecidos de planta, com translocação mínima de tecidos tratados para tecidos não-tratados dentro da mesma planta (National Registration Authority for Agricultural and Veterinary Chemicals, 2002). $\mathrm{O}$ produto, isoladamente ou combinado, tem demonstrado excelente controle de várias espécies de folhas largas e da família Poaceae (Patterson \& Faircloth, 2001; Rawls et al., 2003).

Este trabalho teve como objetivo avaliar a eficiência de herbicidas, aplicados isoladamente ou em mistura, no controle de R. exaltata.

\section{MATERIAL E MÉTODOS}

O experimento foi realizado na localidade de Carvão, município de Campos dos Goytacazes-RJ, onde a infestação de R. exaltata era superior a 95\%. O experimento foi conduzido em área de produção de cana-de-açúcar, em ciclo de cana-soca de terceiro corte, com colheita feita manualmente após queima.

O clima da região, segundo a classificação de Köeppen, é do tipo Awi, com temperatura média em torno de $24{ }^{\circ} \mathrm{C}$ e precipitação anual de $905 \mathrm{~mm}$ (Ometto, 1981), sendo o solo do tipo Cambissolo, cujas características físicas e químicas encontram-se na Tabela 1.

O cultivar de cana-de-açúcar utilizado foi o RB 72454, que tem como principais características: alta produtividade de colmos, elevado teor de sacarose, teor médio de fibra, 
maturação média a tardia, com boa brotação de cana-planta e soca, bom perfilhamento e florescimento ocasional. Apresenta tolerância intermediária ao carvão e resistência à ferrugem e ao mosaico. Possui porte ereto e arquitetura foliar do tipo intermediária (Gheller, 1993).

O delineamento experimental usado foi o de blocos casualizados, com quatro repetições e oito tratamentos, conforme Tabela 2.

As parcelas foram constituídas de cinco linhas, espaçadas de $1,5 \mathrm{~m}$ e com $5 \mathrm{~m}$ de comprimento, constituindo uma área de $37,5 \mathrm{~m}^{2}$. Os herbicidas foram aplicados em pós-emergência, quando as plantas daninhas estavam com aproximadamente 6 a 8 folhas e as plantas de cana com até 10 folhas, utilizando-se pulverizador costal pressurizado, operando em pressão constante de $3,5 \mathrm{kgf} \mathrm{cm}^{-2}$, com bico XR 8003 e volume de calda de $250 \mathrm{~L} \mathrm{ha}^{-1}$. Foi adicionado surfatante $(0,2 \%)$ nos tratamentos com trifloxysulfuron-sodium. As parcelas capinadas receberam uma capina manual na mesma época da aplicação dos herbicidas, aos 45 dias depois do início da brotação da canasoca.

As avaliações de controle de $R$. exaltata foram feitas aos 22 e 81 dias após aplicação dos herbicidas, com quatro amostragens (quadrado de $0,25 \mathrm{~m}^{2}$ ) por parcela. Foi determinado o número de plantas por amostragem, sendo os dados transformados em porcentagem de controle em relação à testemunha sem capina. Considerou-se eficiente o controle igual ou superior a 80\%. A avaliação da toxicidade à cana-de-açúcar foi feita aos 30 dias após a aplicação dos herbicidas.

A produção de colmo foi estimada colhendo-se as três linhas úteis de cada parcela, aos 12 meses de idade da cana-soca.

Para comparação de médias referentes ao controle de $R$. exaltata, às injúrias na planta $\mathrm{e}$ à produtividade dos colmos de cana-de-açúcar foi utilizado o teste de Tukey a 5\% de significância.

Tabela 1 - Resultado das análises granulométrica e química do solo da área experimental. Campos dos Goytacazes-RJ

\begin{tabular}{|c|c|c|c|c|c|c|c|c|c|}
\hline \multicolumn{2}{|c|}{ Característica Física } & \multicolumn{5}{c|}{ Característica Química } \\
\hline Areia & Silte & Argila & $\mathrm{pH}$ & M.O. & $\mathrm{Ca}$ & $\mathrm{Mg}$ & $\mathrm{K}$ & $\mathrm{P}$ & $\mathrm{Al}$ \\
\hline \multicolumn{3}{|c|}{$\left(\mathrm{g} \mathrm{kg}^{-1}\right)$} & & $\left(\mathrm{H}_{2} \mathrm{O}\right)$ & $\left(\mathrm{g} \mathrm{kg}^{-1}\right)$ & \multicolumn{5}{c|}{$\left(\mathrm{mmol}_{\mathrm{c}} \mathrm{kg}^{-1}\right)$} \\
\hline 60 & 380 & 560 & 5,8 & 27,5 & 40,8 & 56,8 & 2,6 & 6,1 & - \\
\hline
\end{tabular}

Análise realizada no Laboratório de Análises Físicas e Químicas de Solo do Campus Avançado da UFRRJ, em Campos dos Goytacazes-RJ.

Tabela 2 - Tratamentos utilizados no experimento. Campos dos Goytacazes-RJ

\begin{tabular}{|c|c|c|}
\hline Tratamento & Dose Comercial & Ingrediente Ativo \\
\hline$(\mathrm{MSMA}+\text { diuron })^{1 /}$ & $8,0 \mathrm{~L} \mathrm{ha}^{-1}$ & $2,88+1,12 \mathrm{~kg} \mathrm{ha}^{-1}$ \\
\hline (Trifloxysulfuron-sodium + ametryne $)^{\frac{2}{}}$ & $1,75 \mathrm{~kg} \mathrm{ha}^{-1}$ & $32,4+1.280 \mathrm{~g} \mathrm{ha}^{-1}$ \\
\hline (Trifloxysulfuron-sodium + ametryne) & $2,0 \mathrm{~kg} \mathrm{ha}^{-1}$ & $37+1.465 \mathrm{~g} \mathrm{ha}^{-1}$ \\
\hline Trifloxysulfuron-sodium ${ }^{3 /}$ & $20 \mathrm{~g} \mathrm{ha}^{-1}$ & $0,37 \mathrm{~g} \mathrm{ha}^{-1}$ \\
\hline Ametryne $^{4 /}$ & $2,5 \mathrm{~L} \mathrm{ha}^{-1}$ & $1,25 \mathrm{~kg} \mathrm{ha}^{-1}$ \\
\hline$(\text { Diuron + paraquat })^{5 /}$ & $3,0 \mathrm{~L} \mathrm{ha}^{-1}$ & $300+600 \mathrm{~g} \mathrm{ha}^{-1}$ \\
\hline Testemunha com capina & - & - \\
\hline Testemunha sem capina & - & - \\
\hline
\end{tabular}

${ }^{1 /}$ Mistura pronta denominada Fortex SC, contendo $360 \mathrm{~g} \mathrm{~L}^{-1}$ de MSMA e $140 \mathrm{~g} \mathrm{~L}^{-1}$ de diuron; ${ }^{2}$ mistura pronta denominada Krismat, contendo

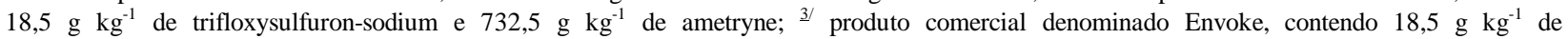
trifloxysulfuron-sodium; ${ }^{4 /}$ produto comercial denominado Gesapax 500 , contendo $500 \mathrm{~g} \mathrm{~L}^{-1}$ de ametryne; ${ }^{5 /}$ mistura pronta denominada Gramocil, contendo $100 \mathrm{~g} \mathrm{~L}^{-1}$ de diuron e $200 \mathrm{~g} \mathrm{~L}^{-1}$ de paraquat. 


\section{RESULTADOS E DISCUSSÃO}

\section{Controle de $R$. exaltata}

O controle de $R$. exaltata acima de $90 \%$ nas duas épocas de avaliações (22 e 88 DAA) foi obtido com os tratamentos trifloxysulfuronsodium+ametryne $\left(37+1.465 \mathrm{~g} \mathrm{ha}^{-1}\right)$, MSMA+ diuron $\left(2,88+1,12 \mathrm{~kg} \mathrm{ha}^{-1}\right)$ e diuron+paraquat $\left(300+600 \mathrm{~g} \mathrm{ha}^{-1}\right)$. Os resultados alcançados com trifloxysulfuron-sodium+ametryne (37+ $1.465 \mathrm{~g} \mathrm{ha}^{-1}$ ) assemelham-se aos encontrados por Moreno (1996), que relata excelente controle de $R$. exaltata ao se utilizar herbicida do grupo químico das sulfoniluréias. O desempenho do trifloxysulfuron-sodium, aplicado isoladamente ou em mistura com ametryne na dose de $32,4+1.280 \mathrm{~g} \mathrm{ha}^{-1}$, não foi satisfatório, embora tenha apresentado sintomas de clorose e redução no crescimento das plantas daninhas (Figura 1).
A capina manual aos 45 dias após a brotação proporcionou controle de $81 \%$ aos 22 DAA e de apenas $43 \%$ aos 81 DAA, observando-se reinfestação de $R$. exaltata.

\section{Toxicidade à cana-de-açúcar}

As plantas de cana-de-açúcar foram afetadas pelas misturas MSMA+diuron e diuron+ paraquat; esta última chegou a causar injúria superior a 20\% (Figura 2). Os herbicidas dos outros tratamentos causaram fitointoxicações leves, inferior a $1 \%$, ou não intoxicaram as plantas. O trifloxysulfuron-sodium, aplicado isoladamente ou em mistura com ametryne, não causou intoxicação nas plantas de cana-deaçúcar, corroborando os resultados de Barros \& Leonel (2001), quando avaliaram as misturas trifloxysulfuron-sodium+ametryne nas doses de $32,4+1.280 \mathrm{~g} \mathrm{ha}^{-1}$ e $37+1.465 \mathrm{~g} \mathrm{ha}^{-1}$, respectivamente.

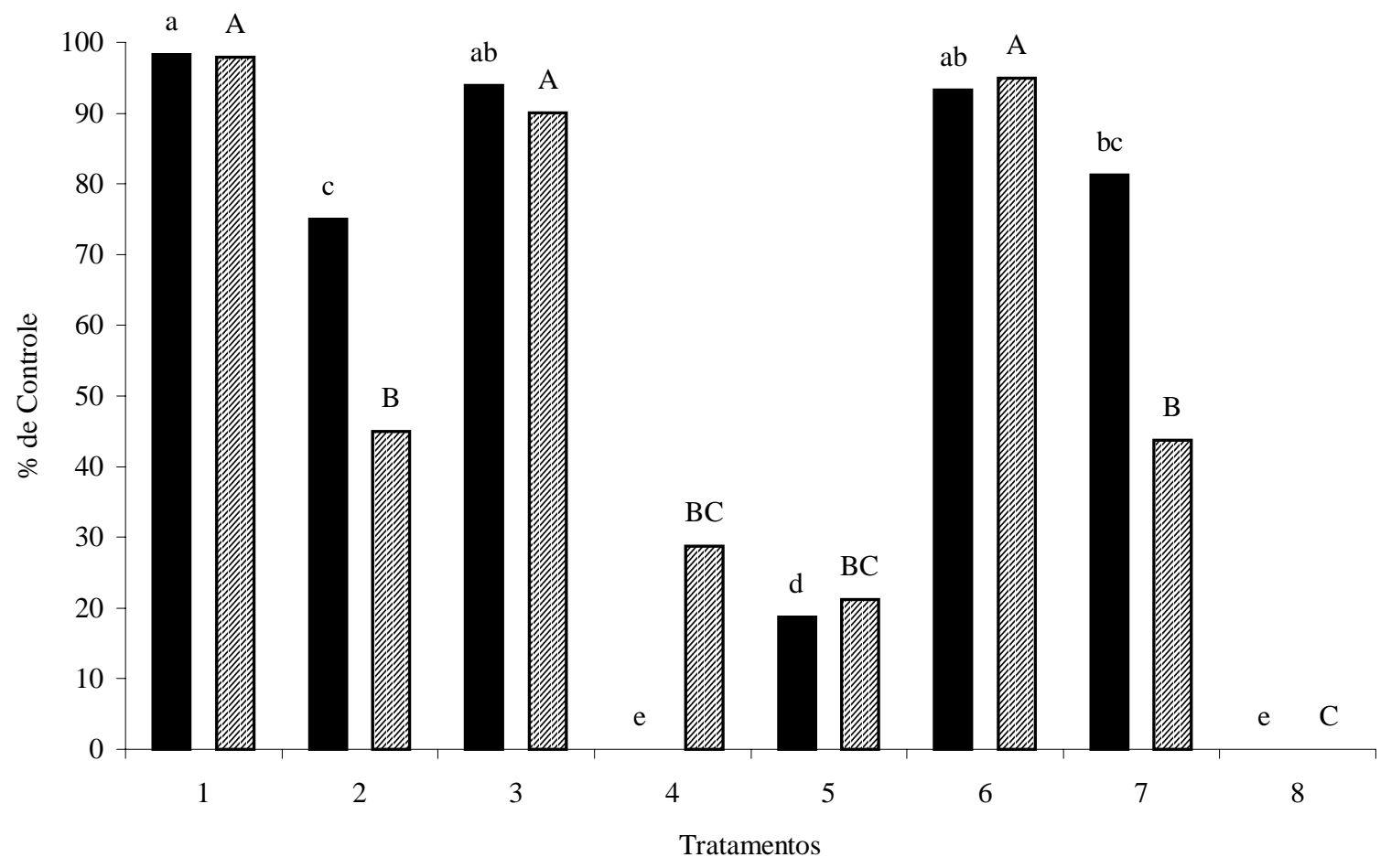

Figura 1 - Percentuais de controle de Rottboellia exaltata, 22 e 81 dias após a aplicação dos tratamentos. Médias seguidas pela mesma letra não diferem entre si pelo teste de Tukey a 5\%. (1 - MSMA + diuron $\left(2,88+1,12 \mathrm{~kg} \mathrm{ha}^{-1}\right) ; 2$ - trifloxysulfuronsodium + ametryne $\left(32,4 \mathrm{~g} \mathrm{ha}^{-1}+1.280 \mathrm{~g} \mathrm{ha}^{-1}\right) ; 3$ - trifloxysulfuron-sodium + ametryne $\left(37 \mathrm{~g} \mathrm{ha}^{-1}+1.465 \mathrm{~g} \mathrm{ha}^{-1}\right) ; 4-$ trifloxysulfuron-sodium $\left(0,37 \mathrm{~g} \mathrm{ha}^{-1}\right) ; 5$ - ametryne $\left(1,25 \mathrm{~kg} \mathrm{ha}^{-1}\right) ; 6$ - diuron + paraquat $\left(300+600 \mathrm{~g} \mathrm{ha}^{-1}\right) ; 7$ - testemunha com capina aos 45 DAE; 8 - testemunha sem capina). 


\section{Produção de colmos}

Maior produção de colmos (Figura 3) foi obtida com diuron+paraquat $\left(300+600 \mathrm{~g} \mathrm{ha}^{-1}\right)$, que foi superior apenas à produção no tratamento com ametryne aplicado isoladamente $\mathrm{e}$ na testemunha sem capina. Trifloxysulfuronsodium+ametryne, nas duas doses aplicadas,

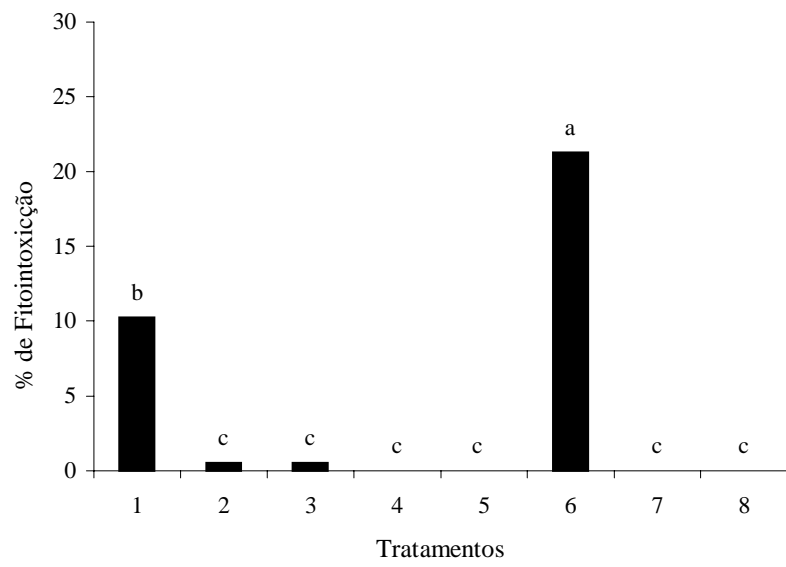

Figura 2 - fitointoxicação causada à cana-de-açúcar em valores médios percentuais. Médias seguidas pela mesma letra não diferem entre si pelo teste de Tukey a 5\%. (1 - MSMA + diuron $\left(2,88+1,12 \mathrm{~kg} \mathrm{ha}^{-1}\right) ; 2$ - trifloxysulfuronsodium+ametryne $\left(32,4+1280 \mathrm{~g} \mathrm{ha}^{-1}\right) ; 3$ - trifloxysulfuronsodium + ametryne $\left(37+1465 \mathrm{~g} \mathrm{ha}^{-1}\right) ; 4$ - trifloxysulfuronsodium $\left(0,37 \mathrm{~g} \mathrm{ha}^{-1}\right) ; 5$ - ametryne $\left(1,25 \mathrm{~kg} \mathrm{ha}^{-1}\right) ; 6$ - diuron + paraquat $\left(300+600 \mathrm{~g} \mathrm{ha}^{-1}\right) ; 7$ - testemunha com capina aos 45 DAE; 8 - testemunha sem capina).

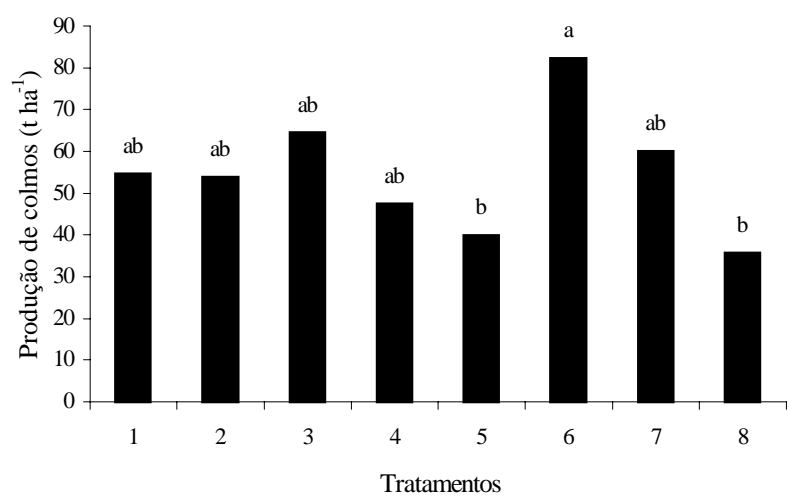

Figura 3 - Produtividade de colmos da cana-de-açúcar em função dos tratamentos. Médias seguidas pela mesma letra não diferem entre si pelo teste de Tukey a 5\% (1 MSMA+diuron $\left(2,88+1,12 \mathrm{~kg} \mathrm{ha}^{-1}\right) ; 2$ - trifloxysulfuronsodium + ametryne $\left(32,4+1.280 \mathrm{~g} \mathrm{ha}^{-1}\right)$; 3 - trifloxysulfuronsodium+ametryne $\left(37+1.465 \mathrm{~g} \mathrm{ha}^{-1}\right) ; 4$ - trifloxysulfuronsodium $\left(0,37 \mathrm{~g} \mathrm{ha}^{-1}\right) ; 5$ - ametryne $\left(1,25 \mathrm{~kg} \mathrm{ha}^{-1}\right) ; 6$ - diuron + paraquat $\left(300+600 \mathrm{~g} \mathrm{ha}^{-1}\right) ; 7$ - testemunha com capina aos 45 DAE; 8 - testemunha sem capina) não diferiu da testemunha capinada e de diuron+paraquat, mostrando boa seletividade para a cana-de-açúcar. Resultados semelhantes foram obtidos por Terra (2003), segundo o qual a mistura de trifloxysulfuron-sodium + ametryne não afetou a produtividade de colmos de cana da variedade RB 72454.

A fitointoxicação causada pelas misturas de MSMA+diuron e diuron+ paraquat à canade-açúcar não levou à redução na produção de colmos, indicando boa recuperação das plantas até a época da colheita.

\section{LITERATURA CITADA}

BARROS, A. C.; LEONEL, D. M. Eficácia e seletividade da mistura trifloxysulfuron-sodium/ametryne para o controle de plantas daninhas na cultura da cana-de-açúcar. R. Brás. Herb., v. 2, n. 3, p. 93-97, 2001.

CONSTANTIN, J. Efeitos de diferentes períodos de controle e convivência da Brachiaria decumbens Stapf. com a cana-de-açúcar (Saccharum spp.). 1993. 98 f. Dissertação (Mestrado em Agronomia) - Universidade Estadual Paulista, Botucatu, 1993.

GHELLER, A. C. A. Características desejáveis e manejo comercial de variedades de cana-de-açúcar. In: CÂMARA, G. M. S.; OLIVEIRA, E. A. M. (Org.) Produção de cana-deaçúcar. Piracicaba: Fundação de Estudos Agrários "Luiz de Queiroz", 1993. p. 65-82.

KUVA, M. A. et al. Períodos de interferência das plantas daninhas na cultura da cana-de-açucar. III-capim brachiaria (Brachiaria decumbens) e capim colonião (Panicum maximum). Planta Daninha, v. 21, n. 1, p. 37-44, 2003.

KUVA, M. A. et al. Peródos de interferência das plantas daninhas na cultura da cana-de-açucar. II-capim brachiaria (Brachiaria decumbens). Planta Daninha, v. 19, n. 3, p.323-330, 2001.

KUVA, M. A. et al. Períodos de interferência das plantas daninhas na cultura da cana-de-açúcar. I - Tiririca. Planta Daninha, v. 18, n. 2, p. 241-251, 2000.

LORENZI, H. Plantas daninhas e seu controle na cultura da cana-de-açúcar. In: SEMINÁRIO DE TECNOLOGIA AGRONÔMICA, 4., 1988, Piracicaba: Anais... Piracicaba: COPERSUCAR, 1988. p. 281-301.

LORENZI, H. Plantas daninhas do Brasil: terrestres, aquáticas, parasitas e tóxicas. 3. ed. Nova Odessa: Instituto Plantarum, 2000. 640 p.

Planta Daninha, Viçosa-MG, v. 22, n. 3, p. 461-466, 2004 
MASCARENHAS, M. T. H. et al. Eficácia do halosulfuron no controle de tiririca (Cyperus rotundus) na cultura da canade-açúcar. Planta Daninha, v. 13, n. 2,p. 69-80, 1995.

MORENO, B. Efecto de varios herbicidas sobre el control de malezas en maíz (Zea mays L.) y su persistencia en el suelo. 1996. 152 f. Dissertação (Mestrado em Agronomia) - Universidad Central de Venezuela, Maracay, 1996.

NATIONAL REGISTRATION AUTHORITY FOR AGRICULTURAL AND VETERINARY CHEMICALS. Evaluation of the new active trifloxysulfuron-sodium in the product Envoke herbicide. Canberra: National Registration Authority for Agricultural and Veterinary Chemicals, 2002. 48 p.

OLIVEIRA Jr. et al. Trifloxysulfuron-sodium: nova opção para o controle seletivo de plantas daninhas na cultura do algodão. R. Oleag. Fibrosas, v. 5, n. 2, p. 345-354, 2001.

OMETTO, J. C. Bioclimatologia vegetal. São Paulo: Agronômica Ceres, 1981. 440 p.
PATTERSON, M. G.; FAIRCLOTH, W. H. Evaluation of CGA 362622 for weed control in cotton. In: McLEAN, K.S.; MONKS, C.D. (Eds). Auburn: Auburn University, Alabama Agricultural Experiment Station, 2001. p. 21.

(Cotton Research Report, 19)

PITELLI, R. A. Interferência de plantas daninhas em culturas agrícolas. Inf. Agropec., v. 11, n. 129, p. 16-27, 1985.

RAWLS, E. K. et al. Envoke: a new herbicide for weed control in U.S. sugarcane. J. Am. Soc. Sugarcane Technol., v. 23, p. 96, 2003.

SEVERO, J. R. Cana-de-açúcar: setor canavieiro terá super safra em 2003/2004. R. Gleba, n. 196, p. 10, 2003.

SHARMA, D.; ZELAYA, O. Competition and control of itchgrass (Rottboellia exaltata) in maize (Zea mays). Trop. Pest Manag., v. 32, p. 101-104, 1986.

TERRA, M. A. Seletividade de diclosulam, trifloxysulfuron-sodium e ametryne a variedades de cana-de-açúcar. 2003. 60 f. Dissertação (Mestrado em Agricultura) - Universidade Estadual Paulista, Botucatu, 2003. 